\title{
Photovoice Data Analysis: Critical Approach, Phenomenological Approach, and Beyond
}

\author{
Kwok Kuen TSANG \\ College of Educational Administration, Beijing Normal University, \\ Beijing, China \\ kktsang@bnu.edu.cn
}

\begin{abstract}
Photovoice is a visual method that has attracted the attention of researchers in the field of education and social sciences in general. However, there are a number of methodological challenges in photovoice research and one of the challenges facing the researchers is the data analysis procedure. This article proposes a strategy for researchers to handle photovoice data analysis which consists of four stages, including a photograph analysis based on the researcher's interpretations, a photograph analysis based on the participants' interpretations, a cross-comparison, and theorization. According to the strategy, researchers should analyze both visual data (participants' voice) and narrative data (interview data) based on their perspectives as well as those of participants in attempt to generate a more credible visual and narrative explanation and theorization of the phenomenon.
\end{abstract}

\section{Keywords}

photovoice - critical theory - phenomenology - visual method - data analysis

\section{Introduction}

Photovoice is a participatory action research method whereby participants identify, represent, and enhance their lives and/or communities through photographic techniques (C. C. Wang, 1999). Since its inception by C. C. Wang and Burris $(1994,1997)$ in the 1990s, photovoice has gained in popularity in the social science literature (Liebenberg, 2018; Sutton-Brown, 2014). It was initially 
treated as a research strategy to promote public health and eventually extended to other research areas like youth (Ho, Rochelle, \& Yuen, 2011), queer (Duran, 2018), refugees (Adams \& Forsyth, 2006; Guerrero \& Tinkler, 2010), leisure (Genoe \& Dupuis, 2013), civic society (Greene, Burke, \& McKenna, 2018), community (Suffla, Kaminer, \& Bawa, 2012), and crime (Ohmer \& Owens, 2013). Education researchers also study education phenomena with photovoice in the last decade (Ciolan \& Mansia, 2017; Harkness \& Stallworth, 2013; Latz \& Mulvihill, 2017; Maria \& Katja, 2019; Tomar \& Stoffel, 2014; T. Wang, 2009). Despite its popularity, photovoice is still a developing and emerging method that is subject to a number of methodological challenges in social research (EvansAgnew \& Rosemberg, 2016; Maria \& Katja, 2019; Power, Norman, \& Dupré, 2014). One of them is data analysis. For example, Oliffe, Bottorff, Kelly, and Haplin (2008) note the difficulties for researchers to make use of the photographs, in addition to the narratives, produced by participants in photovoice data analysis in order to theorize the phenomenon being studied. Power et al. (2014) also identify the tension between participant-led and researcher-led analyses of the photographs in photovoice research. Thus, the article is intended for education researchers, and researchers in other fields, to handle photovoice data analysis. A proposed strategy will be outlined by using my study on the educational trajectory of Hong Kong students studying at a self-financing higher education institution. Two current approaches to photovoice, namely critical and phenomenological approaches, and their limitations in data analysis will be reviewed and the proposed approach will then be discussed.

\section{The Critical Approach to Photovoice}

I call the first approach the critical approach because it is informed by different thoughts of critical theory, such as Freire's theory of critical pedagogy and feminism (C. C. Wang \& Burris, 1997). In addition, it is a participatory action research method, as it seeks to raise people's awareness of the ideological control over their lives, encouraging them to make changes. As noted by C. C. Wang (1999, p. 185), founder of photovoice, the goals of photovoice are " $(1)$ to record and reflect their personal and community strengths and concerns, (2) to promote critical dialogue and knowledge about personal and community issues through group discussions of photographs, and (3) to reach policymakers."

The main theme of these goals is empowerment, which means awakening one's critical consciousness of social forces (re)producing oppressed and disadvantaged social positions (Asaba, Rudman, Mondacad, \& Park, 2014; 
Carlson, Engebretson, \& Chamberlain, 2006). In other words, the critical approach considers photovoice as a strategy to empower participants and bring about social change (Greene et al., 2018). For example, C. C. Wang's (1999) study showed how photovoice can be used as an intervention strategy to empower women to improve their health in rural China. Ohmer and Owens (2013) illustrated how photovoice can be integrated into a crime prevention program to enhance the collective efficacy of community residents in crime prevention. Similarly, Suffla et al. (2012) demonstrated how photovoice can empower young people to get involved in their community to enhance community safety. Finally, T. Wang (2009) showed how photovoice has become an educational means of developing students' critical assessment of the effects of globalization on social life.

To empower participants, photovoice does not only encourage participants to reflexively take and interpret photographs of their lives and/or communities. Thus, photovoice researchers rely on participants to analyze the photographs. To facilitate the participant-led analysis, the researchers invite the participants to join a photo-discussion session when they finish photography based on certain themes over a defined period. In the photo-discussion session, the participants are invited to select and discuss the most important photograph(s) in a group setting. They are also encouraged to share the meanings behind the photograph(s) based on the following SHOWED questions: (1) What do you See here? (2) What is really Happening here? (3) How does this relate to Our lives? (4) Why does this situation, concern, or strength exist? (5) What can we Do about it? (C. C. Wang \& Burris, 1997). In addition, they are asked to codify the issues and themes emerged from their photographs during the group discussion. It is suggested that the process of participant-led analysis may deepen the participants' critical reflections on their lives and therefore enrich their critical awareness of their lives (C. C. Wang \& Burris, 1997).

Accordingly, the main goal of the critical approach to photovoice is empowerment rather than social research. Thus, it is closer to a rigorous empowerment methodology than a research methodology. This does not mean that the critical approach to photovoice does not explain a phenomenon, but that the explanation relies heavily on the participants' analysis of the photographs. Although the participant-led analysis strategy may help participants think critically about their lives and communities (Asaba et al., 2014), this strategy makes it difficult for photovoice research to provide theoretical explanations and/or theorization of phenomena that advance our knowledge, as participants' analyses may rely on common sense knowledge. As a result, the critical approach to photovoice may provide relatively little in-depth theoretical analyses and explanations. 
To overcome the limitations of the critical approach, researchers have developed the phenomenological approach to photovoice in social research. In this approach, photovoice is seen as a method to elicit the meanings participants give to their photographs (Plunkett, Leipert, \& Ray, 2013). Through the analysis of the meanings, researchers can identify what participants have in common when they consciously experience a phenomenon and explain its patterns and/or essence (van Manen, 1997). For example, Baker and Wang (2006) identified the patterns of lived chronic pain experiences among older adults using photovoice. Genoe and Dupuis (2013) explored the meanings of leisure for people with dementia by describing their lived experiences of leisure via photovoice. Similarly, Harkness and Stallworth (2013) used photovoice to understand high school girls' conceptions of mathematics as lived experiences to improve the method of teaching mathematics. Duran (2018) investigated the phenomenon of belonging among queer students of color in a predominantly White institution.

As a research method, especially a method of phenomenological inquiry, photovoice has certain advantages for investigating social phenomena compared with other methods, such as interviews. First, interviews may not accurately reflect the meaningful lived experiences of the participants, as they tend to be influenced by the researcher's agenda and presuppositions (Brunsden \& Goatcher, 2007). In contrast, photovoice allows participants to decide what and how to present and express their thoughts, views, and feelings throughout the research process (Asaba et al., 2014). Thus, photovoice enables the researcher to capture the meaningful lived experiences of the participants regarding a phenomenon (Plunkett et al., 2013). Second, conventional interview methods rely heavily on narratives and words. However, as Kirova and Emme (2006) argued, many layers of lived experiences may not be easily expressed and interpreted by narratives and words. Visual images, such as photographs, may be a useful tool for participants to create deeper meanings of the world, as they can encourage them to reflexively think, recall, reflect, and represent feelings, thoughts, events, and other issues in a particular moment (Glaw, Kable, \& Hazelton, 2017; Raggl \& Schratz, 2004). In this sense, photovoice can be a better method of social investigation.

Similar to the critical approach, the phenomenological approach invites participants to take photographs of their lives and/or communities based on certain themes over a defined period, then to reflectively share and discuss their photographs. Different from the critical approach, the phenomenological approach favors the strategy of researcher-led analysis. It does not mean the researchers ignore the participants' interpretations of the photographs; 
instead they treat the participants' interpretations as narrative data for them to understand participants' lived experiences and analyze phenomena. In order to generate richer data, the researchers may invite participants to join a series of individual or group interviews to discuss the meanings behind the photographs and to write a logbook to record their feelings, thoughts, and ideas when taking photographs (Plunkett et al., 2013). After data collection, the researchers transcribe the interviews and analyze the narrative data to explain the phenomenon being studied.

Accordingly, by the phenomenological approach, the researcher uses photographs to encourage participants to reflect, interpret, and represent the phenomenon being studied. In this regard, photographs only serve as data antecedents rather than data per se (Latz \& Mulvihill, 2017). Thus, in phenomenological photovoice research, only a few formal analyses of photographs pay attention to the narrative data collected from logbooks and interviews (Oliffe et al., 2008). However, photographs, as visual data, provide additional and meaningful information for us to understand participants' interpretations of the world (Harper, 2012). Moreover, visual data can be used to triangulate narrative data to enhance the credibility of photovoice research (Plunkett et al., 2013). In other words, the phenomenological approach to photovoice may not fully use the photographs in the study. This situation may obscure the distinct feature of photovoice, i.e., the visual and narrative representations and explanations of phenomena based on the views (photographs) and voice (interviews) of participants.

A Proposed Data Analysis Strategy for Photovoice

In an attempt to overcome the limitations of current approaches to photovoice data analysis, researchers should respect, balance, and take into account their interpretations of the phenomenon and those of the participants (Ciolan \& Mansia, 2017) as well as recognize participants' photographs and narratives as meaningful data (Oliffe et al., 2008) during data analysis. This practice may not only enable them to avoid distorting the participants' interpretations of the phenomenon, but also help generate theoretical explanations of this phenomenon. To achieve these goals, I propose a data analysis strategy based on current data analysis strategies in participatory visual research (e.g., Glaw et al., 2017; Oliffe et al., 2008; Plunkett et al., 2013). My strategy consisted of four stages, including a photograph analysis based on the researcher's interpretations, a photograph analysis based on the participants' interpretations, a 
cross-comparison, and theorization. To explain the data analysis strategy, I will show how I analyzed my data with eight photographs collected during my research study (see Figure 1).

\subsection{Photograph Analysis Based on the Researcher's Interpretations}

Some researchers (e.g., Oliffe et al., 2008), have suggested that the first step in analyzing data in visual research is to preview visual images based on participants' interpretations of the images and then to review them from the researcher's perspective, to avoid imposing the researcher's interpretations on those of the participants at the beginning of the data analysis. However, experience has taught me that it can be difficult to "bracket" myself when previewing photographs. I found it easy to adopt the participants' interpretations from my perspective, consciously and unconsciously. As a result, the meanings of the photographs may already be distorted at the beginning of the data analysis. To overcome this problem, I chose to first review the photographs from the researcher's perspective without referring to the participants' interpretations, i.e., their narratives related to the photographs. Therefore, in this step, I only conducted an initial analysis of the photographs then developed a preliminary explanation of the phenomenon.

To analyze the photographs, the researcher must categorize them and examine each category, then re-categorize them and re-examine the categories, until saturation. For example, in the study, some photographs represented leisure activities (Photographs 3 and 4). Photograph 3 represents a set of instruments placed on the floor rather than held by students, while Photograph 4 shows basketball courts photographed from a distance. For me, these photographs suggested that there was a certain distance between the students and the leisure activities that interested them. Thus, I classified them in a group labeled "a distance from leisure activities." During the analysis process, I took analytical notes to record my interpretations of the photographs. Table 1 summarizes the themes, sample photographs, and my interpretations of the photographs for each category.

In the initial analysis from the researcher's perspective, I interpreted that the educational experiences of the participants were unhappy. This unhappiness could be related to their educational trajectory by keeping them away from leisure activities, forcing them to attend private tutoring classes, and giving them too much homework to do every day to prepare for the HKDSE, which is a high-stake examination for university admission in Hong Kong. Yet, all of these efforts did not allow them to obtain good results in the HKDSE to enter a publicly funded university. 

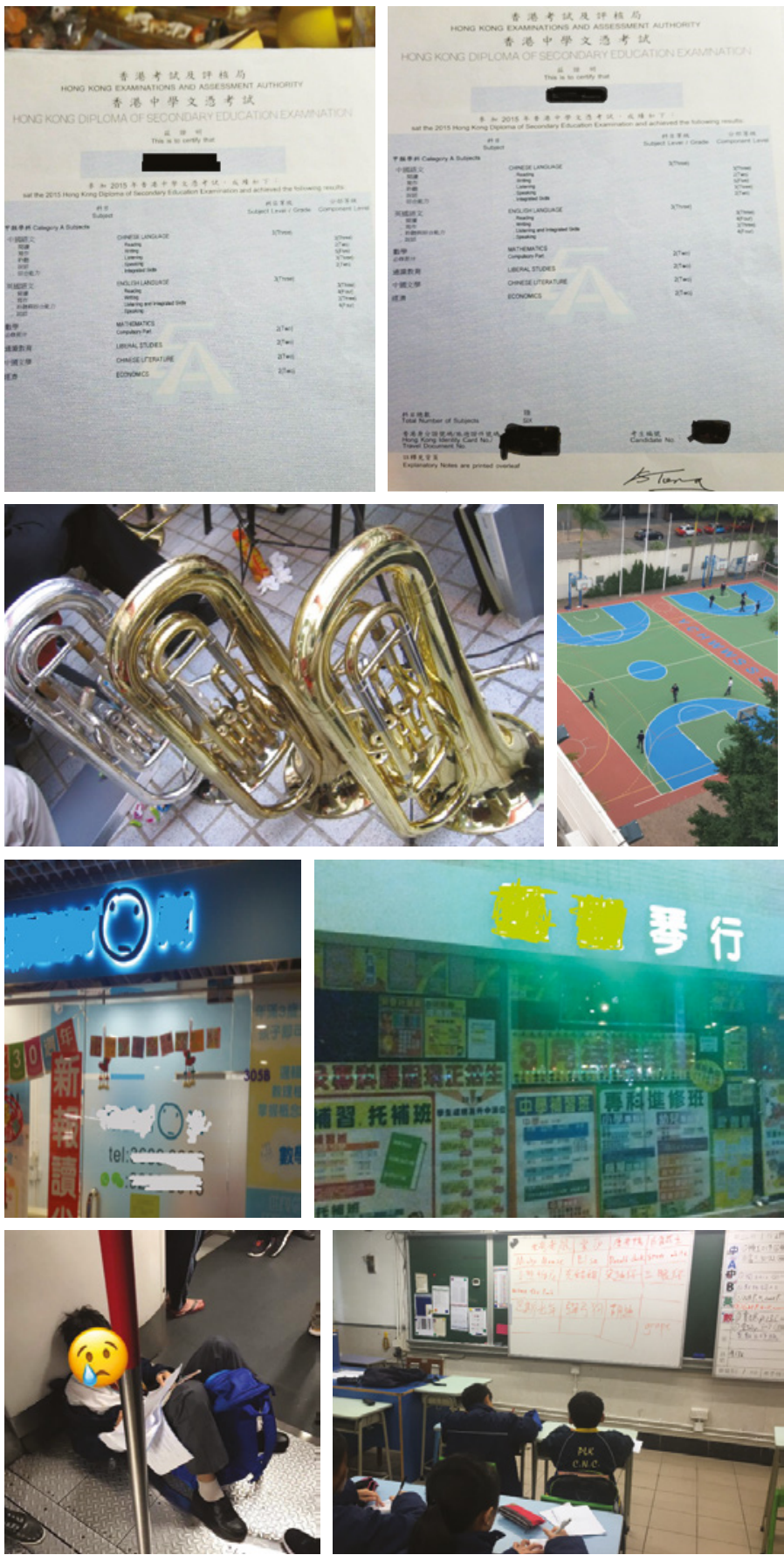

FIGURE 1 Sample photographs for data analysis demonstration 
TABLE 1 Data analysis summary table based on the researcher's interpretations

$\begin{array}{ll}\text { Theme } & \begin{array}{l}\text { Sample Researcher's interpretations } \\ \text { photographs }\end{array}\end{array}$

A distance 3 and 4 from

leisure

activities

Academic 1 and 2 failure

Unhappy $\quad 5$ and 6 private tutoring

Homework 7 and 8 overload
This group of photographs gives me the feeling that the participants were interested in some leisure activities but that they might find it difficult to enjoy them. For example, Photograph 3 represents a set of instruments placed on the floor rather than held by students, and Photograph 4 shows basketball courts photographed from a distance rather than near or on the courts.

All photographs in this category are related to the participants' HKDSE credentials. Looking closely at the photographs, I can see that these credentials are poor examination results. This suggests that the participants were pursuing a degree program at a self-financing higher education institution because of poor performance, which hindered their acceptance into a publicly funded university. As 10 out of 15 participants took this type of photograph, academic failure may be a big issue among participants. Six participants took photographs of private tutoring centers or advertisements for private tutoring classes. For example, Photograph 6 shows various advertisements for private tutoring classes from primary to secondary school displayed on the glass wall of a private tutoring center. Similarly, Photograph 5 shows an unhappy face that is the logo of a private tutoring center. These photographs seem to suggest that Hong Kong students have to attend private tutoring lessons since primary school, but they do not enjoy that.

This group of photographs shows that students are overloaded with homework. In Photograph 8, I can see a group of students studying very hard in a classroom. Moreover, I note the list of 12 homework exercises on the whiteboard on the right that students may be required to complete on the day of the photograph. Photograph 7 also shows a student doing his homework on the Metro. The emoji replacing the student's face is a crying face. It seems to suggest that students are unhappy with the homework overload situation. 


\subsection{Photograph Analysis Based on the Participants' Interpretations}

After conducting an initial analysis of the photographs and developing the preliminary explanation from the researcher's perspective, the researcher must determine whether there are alternative explanations for the photographs, based on the participants' interpretations. Therefore, during the second stage, I carefully studied the details and narratives of the photographs. Similar to the first step, I categorized and re-categorized the photographs and narratives into themes, until saturation. Table 2 summarizes the themes, sample photographs, and examples of participants' interpretations of the photographs.

Through the participants' interpretations of the photographs, I noted that their educational experiences were unhappy, because they were forced to give up their potential and interests to have time to study for the HKDSE. Moreover, these negative experiences were reinforced by their perception that what they had learned was meaningless in their daily lives and did not help them enter a publicly funded university that could improve their chances in life. Therefore, they perceived education as a time-wasting game. Moreover, they noted an internal contradiction in education. Indeed, the education system encouraged all-round development but everything was subordinated to exam results. To a certain extent, this internal contradiction could be related to their educational experiences, although that connection was not identified by the participants' interpretations.

\subsection{Cross-comparison}

After completing the data analysis based on the researcher's interpretations and those of the participants, the researcher must compare the two sets of results. This means that he or she must compare photographs with photographs, narratives with narratives, photographs with narratives, photographs and narratives with categories, categories with categories, themes with themes between the two sets of results. The purpose of this stage is to create a "dialogue" between the researcher's interpretations and those of the participants to develop an integrative explanation of the phenomenon.

For example, the themes "unhappy private tutoring" and "hard-working students" that emerged from my interpretations were similar to the theme "exhausted learning for the future" that emerged from the analysis based on the participants' interpretations. All of these themes suggested that the participants were stressed and exhausted because of their studies, especially going to private tutoring classes. From the participants' interpretations, I also found that they had to study hard because they were told that, as one mentioned, "if I didn't work hard now, I could hardly compete with others in the future" (Student B; see Table 2). Therefore, I re-categorized these photographs and narratives into a theme labeled "stressful education." 
TABLE 2 Data analysis summary table based on participants' interpretations

$\begin{array}{lll}\text { Theme } & \begin{array}{l}\text { Sample } \\ \text { photographs }\end{array} & \text { Examples of participants' interpretations } \\ & \end{array}$

Education is a 1 and 2 time-wasting game

Exhausted 5,7 , and 8

learning for

the future
"In my opinion, I think education in Hong Kong is a time-wasting game, such as doing past papers, going to tutoring classes, reciting books, attending mock exams. For example, doing past Mathematics papers to review the long formula that we will never use again, or doing past Chinese papers to understand questions that the author did not even think about" (Student H). "Having reflected on my learning experience of more than 20 years, I asked myself a question: what did I learn? I felt that my school life was made for exams and that by passing these exams, I could ultimately get into a good university. Yet, I couldn't help but ask myself what I had learned. The practical applications of my learning are so limited that I can rarely apply this knowledge, e.g., the Pythagorean Theorem, Classical Chinese, to my daily life" (Student K). "Students in Hong Kong are trapped on a treadmill of endless exams. Every student wants to stand out from the crowd, to be the winner who gets into university. We keep training ourselves by practicing past papers and exam preparations. All we want is to avoid mistakes and ensure good results in our exams" (StudentJ).

"My mom has arranged for me to take classes at different tutoring schools since Primary 3. As expensive as tutoring classes were, she considered this expense necessary. She always said that if I didn't work hard now, I could hardly compete with others in the future. Her words made me go to tutoring classes after school and stay there until night-time every day" (Student B).

"Going to school and attending tutoring classes after school were part of my daily life. All this was part of my daily life" (Student A).

"No entertainment and relaxation, but lessons, exercises, and homework" (Student J). 
TABLE 2 Data analysis summary table based on participants' interpretations (cont.)

$\begin{array}{lll}\text { Theme } & \begin{array}{l}\text { Sample } \\ \text { photographs }\end{array} & \text { Examples of participants' interpretations } \\ & \end{array}$

Suppressed 3 and 4
potential and
interests

"After entering Form 4 (Grade 10), my school started to pressure us. I had to do a lot of past papers every day, and I had no choice but to give up my piano lessons for the sake of my studies. I even threw away my piano, which was the only way to release my emotional stress. My stress increased after that" (Student A).

"Teachers have the power to decide who will participate in extracurricular activities. Regardless of the potential and interest of a student, he or she is less likely to be selected for an activity than students with good academic results. It is compulsory to attend supplementary classes if your academic performance is below average. Priority is given to supplementary classes even if you have other activities at the same time. In other words, if your academic results are below average, your right to attend activities is limited" (Student M).

"Having given up my interests, I gradually became an aimless learner, a by-product of the education system" (Student O).

Internal 6 contradiction in education
"I want to share this picture with you because it reveals and satirizes the Hong Kong education system. A music school is supposed to be a place to impart music knowledge and techniques. Its environment should be full of musical instruments. The walls should display posters of different music classes. However, in the picture, what I see is a music school displaying countless posters of tutoring classes for primary or secondary school students. It truly reflects how exam-oriented the Hong Kong education system is. Society wants to focus on all-round development, but what matters most is academic achievement. The focus is only on exams and not on non-academic skills and interests" (Student B). 
In addition, I integrated similar themes in the cross-comparison. For example, I noted that the meanings of the following themes were similar: the theme "a distance from leisure activities" emerged from my interpretations and the theme "suppressed potential and interests" emerged from the analysis based on the participants' interpretations. They showed that participants did not have the opportunity to develop their potential and interests in school. The participants' narratives suggested that they were institutionally forced to give up their potential and interests, resulting in a sense of dehumanization (e.g., the words of Student $\mathrm{O}$ in Table 2). Therefore, I integrated them into a theme labeled "dehumanizing schooling" to capture the meaning of the institutional suppression of students' potential and interests and the sense of dehumanization.

Sometimes two themes with different meanings can be found in the same photographs, depending on the researcher's interpretations and those of the participants. For instance, I found that the same photographs were grouped under the theme "academic failure" based on my interpretations and the theme "education is a time-wasting game" based on those of the participants. However, the two themes had different meanings. In this case, I analyzed the visual and narrative data, including the narratives created by my interpretations of the photographs, again and again. By analyzing my words and the participants' words and photographs, I noticed that the photographs of the HKDSE credentials represented the idea of "educational instrumentalism." This suggested that the participants viewed education as an instrument for achieving good results in the HKDSE and getting into a publicly funded university rather than an end in itself.

Moreover, the researcher may find that interesting themes emerge from his or her perspective or that of the participants. In this case, the researcher may choose to keep the theme. For example, I kept the theme "internal contradiction in education" derived from the analysis of the participants' perspective.

\subsection{Theorization}

The last step of the data analysis is theorization. In this step, the researcher must identify the relationships between the themes developed during the cross-comparison to generate visual and narrative representations and explanations of the phenomenon studied. For example, based on the above data analysis, I proposed the following theorization:

Students studying at a self-financing higher education institution may suffer from negative educational experiences, which may dominate their lives throughout their school years, from primary to higher education. For example, participants showed that their primary and secondary school education was 
stressful because they had to do many exercises assigned by their schoolteachers every day (as suggested by Photograph 8 representing a list of 12 homework exercises on a whiteboard), but they also had to attend private tutoring lessons after school. As Student A commented, "going to school and going to tutoring classes after school were part of my daily life. All this was part of my daily life" (this situation was also reflected in Photograph 6 representing different advertisements for private tutoring classes, from primary to secondary school, implying that Hong Kong students must attend many private tutoring classes starting in primary school). Participants stated that this situation made them feel unhappy because they had "no entertainment and relaxation, but lessons, exercises, and homework" (Student J; the unhappiness was visualized by the unhappy face as the logo of a private tutoring center in Photograph 5 and the crying emoji replacing the face of the student doing his homework in the Metro in Photograph 7).

This unhappiness was also illustrated in secondary school, as the dehumanizing school system institutionally forced the participants to give up their interests to spend time on H KDSE preparation (for example, Photograph 3 shows a set of instruments placed on the floor rather than held by students, and Photograph 4 shows basketball courts photographed from a distance. These two photographs reveal the psychological distance separating the participants from their interests and leisure activities). For example, Student M stated that her school institutionally prevented students, especially those with poor academic performance, from attending extracurricular activities to develop their non-academic potential and interests. This institutional suppression of their potential and interests made students feel dehumanized. For instance, Student $\mathrm{O}$ stated, "having given up my interests, I gradually became an aimless learner, a by-product of the education system."

Further analysis of the data revealed that there was an ideology legitimizing stressful education, dehumanizing schooling, and the negative educational experiences of students in Hong Kong. This ideology was educational instrumentalism. It emphasized that the ultimate goal of education was to pass the HKDSE to have the opportunity to enter a publicly funded university and thus have chances in life. The ideology was represented by Photographs 1 and 2 and the participants' interpretations of these photographs. For instance, a participant made the following comment on Photographs 1 and 2: "Students in Hong Kong are trapped on a treadmill of endless exams. Every student wants to stand out from the crowd, to be the winner who gets into university. We keep training ourselves by practicing past papers and exam preparations. All we want is to avoid mistakes and ensure good results in our exams" (Student J). Influenced by this ideology, education was conceived as a dehumanizing 
institution forcing students to study hard to prepare for the HKDSE, resulting in unhappiness. Nevertheless, the participants did not obtain good enough results in the HKDSE (as shown in Photographs 1 and 2) to get into a publicly funded university. Therefore, they found that what they had learned for many years was not useful in their daily lives. As a result, they felt that "education in Hong Kong is a time-wasting game" (Student $\mathrm{H}$ ).

It should be noted that educational instrumentalism implies the alienating effect of education in Hong Kong. This alienation was visualized by Photograph 6 representing the internal contradiction in education in Hong Kong and Student B's interpretation of the photograph (see Table 2).

\section{$5 \quad$ Conclusion}

Photovoice as a developing and emerging visual method has received increasingly more attention in various fields of the social sciences over the last decade. As mentioned above, researchers do encounter different methodological challenges when doing photovoice research (Evans-Agnew \& Rosemberg, 2016; Maria \& Katja, 2019). One of the challenges highlighted here is to balance the perspectives of participants and researchers and handle visual and narrative data, in order to generate theoretical explanations or theorization of phenomena. This article proposes a strategy of photovoice data analysis consisted of four stages, including a photograph analysis based on the researcher's interpretations, a photograph analysis based on the participants' interpretations, a cross-comparison, and theorization. To summarize, the proposed strategy analyzes both visual data (participants' voice) and narrative data (interview data) and encourages the researcher to analyze the data based on his or her interpretations and those of participants. Thus, it can better utilize the participants' photographs and narratives and the researcher's narratives to understand a phenomenon, which in turn generate a more credible visual and narrative representation and explanation of the phenomenon.

\section{Acknowledgements}

The research project is funded by the International Joint Research Project, Faculty of Education, Beijing Normal University, China. (ICER201907).

I would like to say thank you to Ms. CHANG Linjia, Ms. QIN Qingyan, and Mr. LI Guanyu for their assistance in the research. 


\section{References}

Adams, C. M., \& Forsyth, P. B. (2006). Proximate sources of collective teacher efficacy. Journal of Educational Administration, 44(6), 625-642. https://doi:10.1108/095782 30610704828 .

Asaba, E., Rudman, D. L., Mondacad, M., \& Park, M. (2014). Visual methodologies: Photovoice in focus. In S. Nayar \& M. Stanley (Eds.), Qualitative research methodologies for occupational science and therapy (pp. 155-173). Routledge.

Baker, T. A., \& Wang, C. C. (2006). Photovoice: Use of a participatory action research method to explore the chronic pain experience in older adults. Qualitative Health Research, 16(10), 1405-1413. https://doi:10.1177/1049732306294118.

Brunsden, V., \& Goatcher, J. (2007). Reconfiguring photovoice for psychological research. The Irish Journal of Psychology, 28(1-2), 43-52. https://doi:10.1080/03033910. 2007.10446247.

Carlson, E. D., Engebretson, J., \& Chamberlain, R. M. (2006). Photovoice as social process of critical consciousness. Qualitative Health Research, 16(6), 836-852. https:// doi:10.1177/1049732306287525.

Ciolan, L., \& Mansia, L. (2017). Reframing photovoice to boost its potential for learning research. International Journal of Qualitative Methods, 16, 1-15. https://doi:10 $.1177 / 1609406917702909$.

Duran, A. (2018). A photovoice phenomenological study exploring campus belonging for queer students of color. Journal of Student Affairs Research and Practice. https:// doi:10.1080/19496591.2018.1490308.

Evans-Agnew, R. A., \& Rosemberg, M.-A. S. (2016). Questioning photovoice research: Whose voice? Qualitative Health Research, 26(8), 1019-1030. https://doi:10.1177/ 1049732315624223 .

Genoe, R., \& Dupuis, S. (2013). Picturing leisure: Using photovoice to understand the experience of leisure and dementia. The Qualitative Report, 18(11), 1-21.

Glaw, X., Kable, A., \& Hazelton, M. (2017). Visual methodologies in qualitative research: Autophotography and photo elicitation applied to mental health research. International Journal of Qualitative Methods, 16, 1-8. https://doi:10.1177/1609406917748215.

Greene, S., Burke, K. J., \& McKenna, M. K. (2018). A review of research connecting digital storytelling, photovoice, and civic engagement. Review of Educational Research, 88(6), 844-878. https://doi:10.3102/0034654318794134.

Guerrero, A. L., \& Tinkler, T. (2010). Refugee and displaced youth negotiating imagined and lived identities in a photography-based education project in the United States and Colombia. Anthropology \& Education Quarterly, 41(1), 55-74. https:// doi:10.1111/j.1548-1492.2010.01067.x.

Harkness, S. S., \& Stallworth, J. (2013). Photovoice: Understanding high school females' conceptions of mathematics and learning mathematics. Educational Studies in Mathematics, 84(3), 329-347. https://doi:10. $1007 /$ s 1 0649-013-9485-3. 
Harper, D. (2012). Visual sociology. Routledge.

Ho, W. C., Rochelle, T. L., \& Yuen, W. K. (2011). 'We are not sad at all': Adolescents talk about their 'city of sadness' through photovoice. Journal of Adolescent Research, 26(6), 727-765. https://doi:10.1177/0743558410391255.

Kirova, A., \& Emme, M. (2006). Using photography as a means of phenomenological seeing: "Doing phenomenology" with immigrant children. Indo-Pacific Journal of Phenomenology, 6, 1-12.

Latz, A. O., \& Mulvihill, T. M. (2017). Photovoice reserach in education and beyond: A practical guide from theory to exhibition. Routledge.

Liebenberg, L. (2018). Thinking critically about photovoice: Achieving empowerment and social change. International Journal of Qualitative Methods, 17, 1-9. https:// doi:10.1177/1609406918757631.

Maria, W., \& Katja, G. G. (2019). Challenges when photovoices is used as a research method in the school setting. Paper presented at the The 9th Nordic Health Promotion Research Conference at Roskilde University. Health: Societal responsibility or individual obligation?, 12-14 June, 2019. Roskilde, Denmark.

Ohmer, M. L., \& Owens, J. (2013). Using Photovoice to empower youth and adults to prevent crime. Journal of Community Practice, 21(4), 410-4333. https://doi:10.108o/ 10705422.2013 .842196$.

Oliffe, J. L., Bottorff, J. L., Kelly, M., \& Haplin, M. (2008). Analyzing participant produced photographs from an ethnographic study of fatherhood and smoking. Research in Nusing \& Health, 31, 529-539. https://doi:10.1002/nur.20269.

Plunkett, R., Leipert, B. D., \& Ray, S. L. (2013). Unspoken phenomena: Using the photovoice method to enrich phenomenological inquiry. Nursing Inquiry, 2o(2), 156-164. https://doi:10.1111/j.1440-1800.2012.00594.x.

Power, N. G., Norman, M. E., \& Dupré, K. (2014). Rural youth and emotional geographies: How photovoice and words-alone methods tell different stories of place. Journal of Youth Studies, 17(8), 1114-1129. https://doi:10.1080/13676261.2014.881983.

Raggl, A., \& Schratz, M. (2004). Using visuals to release pupils' voices: Emotional pathways into enhancing thinking and reflecting on learning. In C. J. Pole (Ed.), Seeing is believing? Approaches to visual research (pp. 147-162). Emerald.

Suffla, S., Kaminer, D., \& Bawa, U. (2012). Photovoice as community engaged research: The interplay between knowledge creation and agency in a South African study on safety promotion. Journal of Psychology in Africa, 22(4), 517-528.

Sutton-Brown, C. (2014). Photovoice: A methodological guide. Photography and Culture, 7(2), 169-185. https://doi:10.2752/175145214X13999922103165.

Tomar, N., \& Stoffel, V. (2014). Examining the lived experience and factors influencing education of two student veterans using photovoice methodology. The American Journal of Occupational Therapy, 68(4), 430-438.

van Manen, M. (1997). Researching lived experience : Human science for an action sensitive pedagogy (2nd ed.). Althouse Press. 
Wang, C. C. (1999). Photovoice: A participatory action research strategy applied to women's health. Journal of Woman's Health, 8(2), 185-192.

Wang, C. C., \& Burris, M. A. (1994). Empowerment through photo novella: Portraits of participation. Health Education Quarterly, 21(2), 171-186.

Wang, C. C., \& Burris, M. A. (1997). Photovoice: Concept, methodology, and use for participatory needs assessment. Health Education \& Behavior, 24(3), 369-387.

Wang, T. (2009). Using photovoice for assessment in teacher education and examining the impacts of globalization on China. Paper presented at the 2009 Australian Association for Research in Education (AARE) International Research Conference, Canberra, Australia. 